\title{
The Study of the Conditions of Cooling on the Structure and Properties of Castings Steel H11
}

\author{
Natalia V. Larionova, \\ Alexander M. Tokmin and Oleg A. Masanskii* \\ Siberian Federal University \\ 79 Svobodny, Krasnoyarsk, 660041, Russia
}

Received 26.01.2018, received in revised form 07.04.2018, accepted 12.05.2018

Results of researches of temperature fields of process of crystallization of the castings of the alloyed steel received by electroslag kokilny casting are considered. Microstructures of models of the castings received under various refrigerating conditions are shown and their mechanical properties are presented.

Keywords: temperature field, solidification, die steel, electroslag chill casting.

\section{Исследование условий охлаждения на структуру и свойства отливок из стали 4Х5МФС}

\author{
Н.В. Ларионова, А.М. Токмин, О.А. Масанский \\ Сибирский федеральный университет \\ Россия, 660041, Красноярск, пр. Свободныий, 79
}

\begin{abstract}
Рассмотрены результаты исследования температурных полей процесса кристаллизации отливок из легированной стали, полученных электрошлаковым кокильным литьем. Показаны микроструктуры образиов отливок, полученных при различных условиях охлаждения, $и$ представлены их механические свойства.
\end{abstract}

Ключевые слова: температурное поле, кристаллизация, штамповая сталь, электрошлаковое кокильное литье.

(C) Siberian Federal University. All rights reserved

* Corresponding author E-mail address: lnv2002@yandex.ru, tam550@yandex.ru 


\section{Введение}

Использование современных методов и принципов решения непростых задач в литейном производстве позволяет изменить механические, эксплуатационные и технологические свойства изделий из легированных сталей. Кинетика зарождения и роста кристаллов оказывает существенное влияние на макро- и микроструктуру отливки. Процесс формирования отливок зависит от особенностей теплообмена, происходящих при кристаллизации. Необходимо уделять особое значение геометрическим и физическим свойствам отливок и формы, характеру течения жидкого расплава, выделению теплоты кристаллизации в материале отливки, особенностям механизма процесса затвердевания охлаждающего сплава, изменению теплофизических коэффициентов материалов отливки и формы и т.д. Применение электрошлакового кокильного литья (ЭКЛ) способствует получению заготовок с регулируемой структурой и с заданными свойствами в результате того, что при заполнении формы металлом шлак перемещается в верхнюю часть отливки и обогревает ее в процессе охлаждения. Такой способ литья позволяет получить эффект направленной кристаллизации в заготовках.

\section{Моделирование процесса кристаллизующейся отливки}

В данной работе рассмотрена возможность регулирования теплового поля при криталлизации изделий из легированной стали, полученных методом электрошлакового кокильного литья, с использованием различной геометрии кокиля и применения принудительного охлаждения различных участков кокиля.

Как известно, применение ЭКЛ позволяет получать фасонные отливки различной номенклатуры, массы и назначения [1]. При заливке металла со шлаком на носик тигля и в кокиль первым попадает шлак, а затем металл, покрытый сверху шлаком. Вследствие того что шлак имеет высокую жидкотекучесть, а при заливке реализуется ламинарное течение, перемешивание металла и шлака не происходит. Шлак, перемещаясь снизу вверх, покрывает стенки кокиля, образуя гарнисаж, вытесняется в верхнюю часть. В результате чего в процессе кристаллизации металла происходит обогревание отливки, создавая большое термическое сопротивление. Таким образом, применение ЭКЛ позволяет отказаться от использования защитных покрытий внутренней поверхности кокиля и устройств, обогревающих верхнюю часть отливки.

Учитывая, что тепловое поле определяет структуру отливки, формирующуюся при кристаллизации, изменение геометрических размеров кокиля, толщины гарнисажа и тепловой насадки, применение принудительного охлаждения приводит к изменению конфигурации и интенсивности теплового потока. Для оценки влияния теплообмена между формирующейся структурой отливки, гарнисажа и кокиля было выполнено моделирование процесса охлаждения с применением программного комплекса ANSYS.

Проводились расчеты по оптимизации охлаждения отливок при электрошлаковом кокильном литье легированной стали 4Х5МФС с целью исследования влияния скорости кристаллизации на структуру охлаждаемой отливки [2, 3]. Для этого была составлена расчетная схема кристаллизующейся отливки при ЭКЛ, в которой использовались параметры, принятые для моделирования полей отливок (табл. 1).

$$
-489-
$$


Результаты моделирования представлены на рис. 1. Рассмотрены тепловые поля моделей с одинаковыми геометрическими размерами кокиля (толщина стенки кокиля составляла 50 мм, толщина донной части 120 мм, толщина верхнего шлакового слоя 60 мм).

В данном случае рассматривались следующие варианты: первая модель - без охлаждения (рис. 1a), вторая - принудительное охлаждение дна без шлака между залитым металлом и кокилем (рис. 1б), третья - принудительное охлаждение боковой части (рис. 18). Следует обратить внимание, что цветовая гамма полей распределения температуры, представленных на рис. $1 a$ и рис. 16, , различна в зависимости от конкретных условий получения отливки.

Таблица 1. Параметры, принятые для моделирования тепловых полей отливок

Table 1. Parameters are accepted for the thermal field modeling of moldings

\begin{tabular}{|c|c|}
\hline Коэффициент теплопроводности расплавленного металла, Вт/м град & 27 \\
\hline Коэффициент теплопроводности шлака, Вт/м град & 1,16 \\
\hline Плотность металла, кг/м³ & 7495 \\
\hline Плотность шлака, кг/м³ & 2800 \\
\hline Температура заливки жидкого металла, ${ }^{\circ} \mathrm{C}$ & 1560 \\
\hline Температура окружающей среды, ${ }^{\circ} \mathrm{C}$ & 20 \\
\hline Коэффициент теплоотдачи металл-воздух, Вт/м² К & 10 \\
\hline Коэффициент теплоотдачи шлак-воздух, Вт/м² K & 3,8 \\
\hline
\end{tabular}

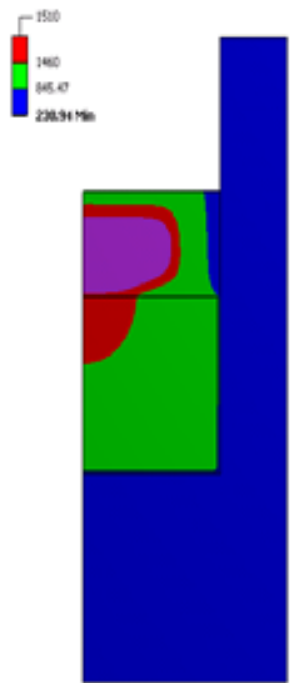

a

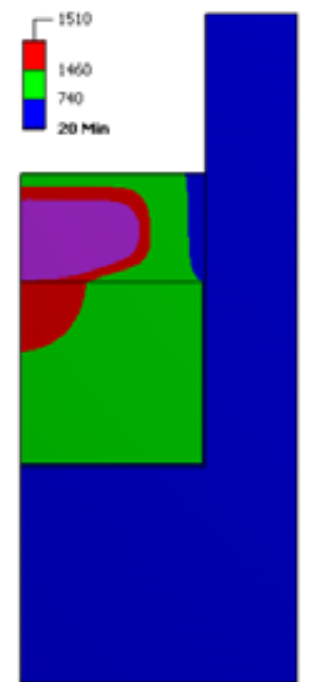

6

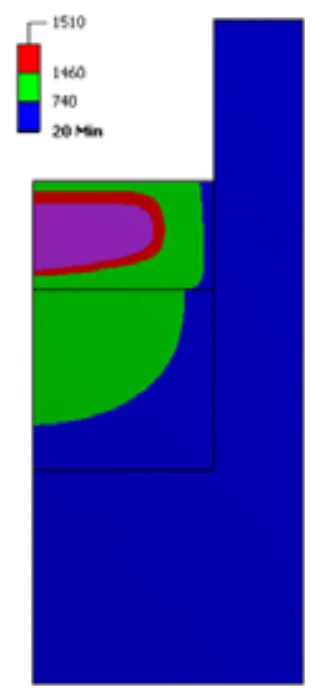

B

Рис. 1. Модель распределения температурных полей спустя 1080 с после заливки расплавленного металла в форму: а - без охлаждения; б - с принудительным охлаждением боковой части; в - с принудительным охлаждением дна без шлака между залитым металлом и кокилем

Fig. 1. Distribution model of thermal fields 1080 seconds after the pouring of molten metal: a - without cooling; $\sigma$ - with forced sidepiece cooling; $\mathrm{B}-$ with forced cooling of the bottom without cinder between metal and chill mold 


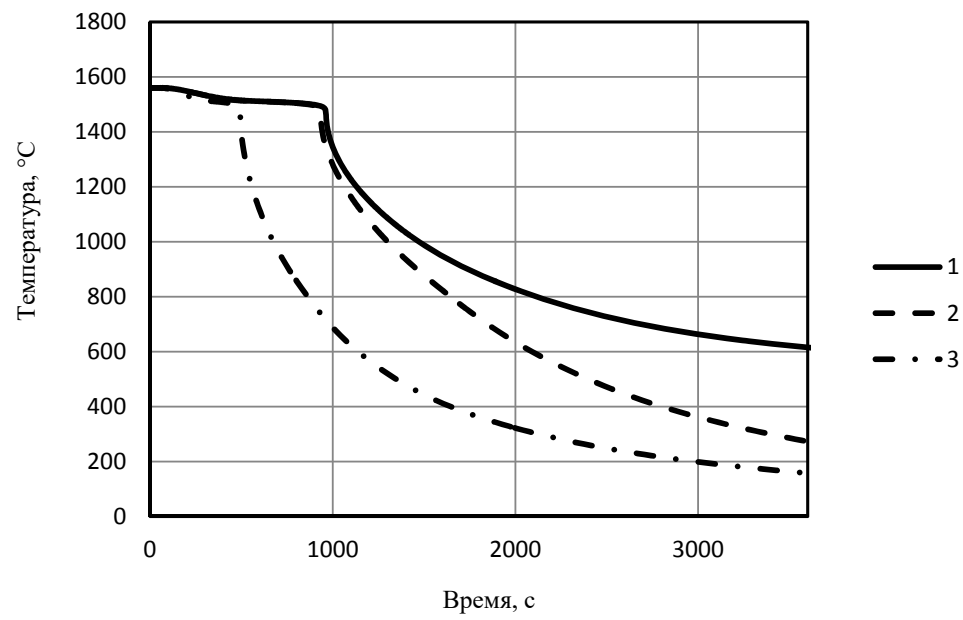

Рис. 2. График зависимости температуры верхней точки отливки от времени

Fig. 2. Time-dependence chart of the temperature of the highest molding point

Отчетливо наблюдаются значительные различия в конфигурации и расположении температурных зон. Температура в середине слитка в первом случае выше, а нагрев стенок кокиля в остальных случаях происходит не так интенсивно. Температура водоохлаждаемых частей кокиля во втором и третьем случаях имеет практически постоянное значение, что отражается на процессе кристаллизации и формировании структуры. Как и следовало ожидать, скорость охлаждения отливки при отсутствии гарнисажа, т.е. в случае непосредственного контакта с кокилем, значительно выше. Однако это увеличение наблюдается лишь по истечении $400-500$ с с момента заливки (рис. 2). Это указывает на время первичной кристаллизации, что приводит к изменению дендритной структуры.

По полученным расчетным данным были построены температурные зависимости верхней точки отливки, находящейся в верхней части, от времени (рис. 2). На графике рассматриваемые модели без охлаждения - кривая 1 , с принудительным охлаждением боковой части - кривая 2 , с принудительным охлаждением дна без шлака между залитым металлом и кокилем - кривая 3. График показывает, что наибольшая скорость охлаждения имеет отливка, в которой отсутствует шлак между металлом и кокилем. В начальный период кристаллизации наблюдаем наибольшую плотность теплового потока. В результате плотного контакта металла со стенками кокиля и принудительного охлаждения дна плотность теплового потока возрастает и скорость кристаллизации увеличивается по сравнению с остальными отливками.

Изменение температуры в верхней точке отливки, к которой не применяется принудительное охлаждение (кривая 1) (рис. 2), происходит менее интенсивно.

Для более детального рассмотрения по полученным данным были построены температурные зависимости отливки и кокиля от времени (рис. 3). После заливки жидкого металла температура наружной поверхности кокиля повышается, что приводит к значительным тепловым потерям. Толщина стенок кокиля существенно влияет на интенсивность поглощения ею тепла, а также на скорость затвердевания отливки. При заливке расплавленного металла под слоем шлака происходит интенсивное охлаждение шлака у стенок кокиля. Одновременно происходит 


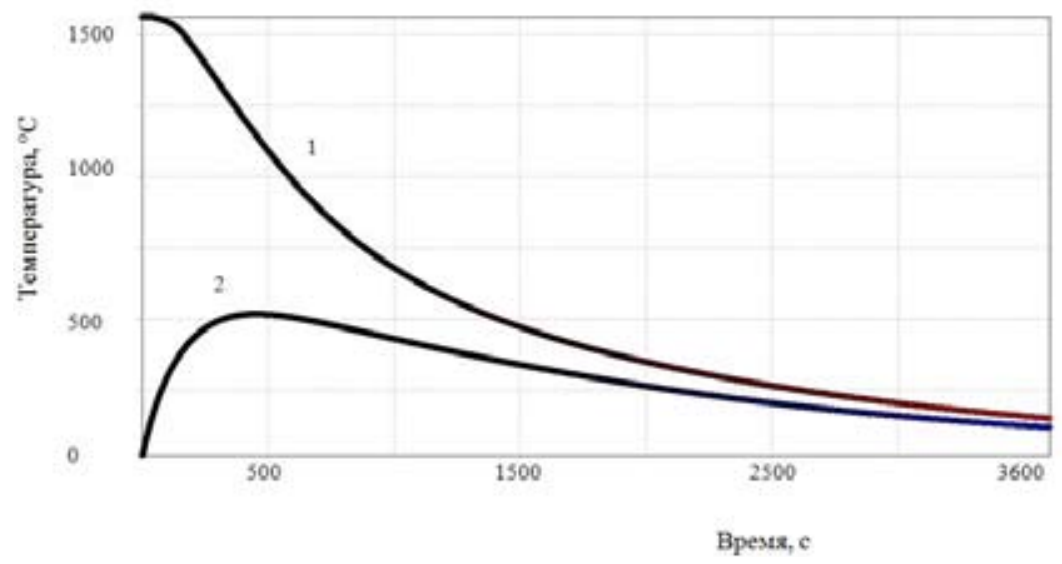

Рис. 3. Зависимость температуры отливки (1) и стенки кокиля (2) от времени охлаждения отливки без охлаждения

Fig. 3. Temperature dependence of molding and chill mold side of cooling time without forced cooling

интенсивный разогрев стенок кокиля и увеличение температуры с момента соприкосновения с жидким шлаком, в дальнейшем температура отливки и кокиля снижаются с постепенным уменьшением градиента температур между кокилем и отливкой (рис. 3).

\section{Микроструктура отливок}

Скорость кристаллизации отливок оказывает во многом определяющее влияние на дисперсность дендритной структуры, а также на ликвационные процессы. Микроструктура отливок с принудительным охлаждением имеет более дисперсную структуру (рис. 4б), расстояние между ветвями дендритов наименьшее по сравнению с отливками обычного охлаждения (рис. 4a).

В ходе работы изучены основные закономерности формирования структуры при разных скоростях охлаждения, установлены зависимости механических свойств от скорости охлажде-

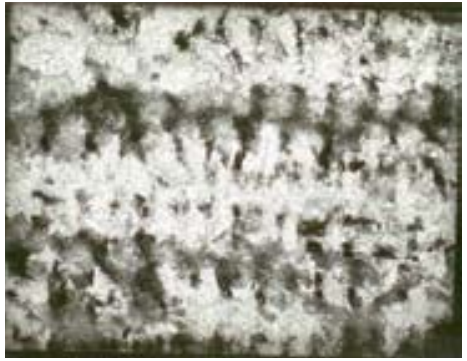

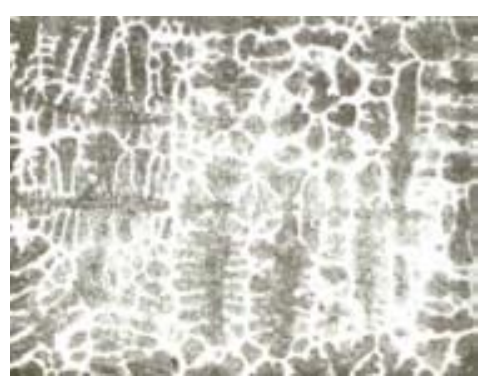

6

Рис. 4. Микроструктура отливок, полученных при разном распределении температурных полей: a - без охлаждения; б - с принудительным охлаждением боковой части

Fig. 4. Moldings microstructure which was obtained with different thermal field distribution: a - without cooling; б-with forced sidepiece cooling 
Таблица 2. Механические свойства образцов, полученных при различных скоростях охлаждения

Table 2. Mechanical characteristics of samples which were obtained with different cooling velocities

\begin{tabular}{|c|c|c|c|c|c|}
\hline № отливки & $\sigma_{\mathrm{s}}, \mathrm{MПа}$ & $\sigma_{\mathrm{t}}, \mathrm{MПа}$ & $\delta, \%$ & $\Psi, \%$ & $\mathrm{KCU}$, МДж/м² \\
\hline 1 & 1327 & 1139 & 5,9 & 10,4 & 0,17 \\
\hline 2 & 1633 & 1331 & 7,24 & 26,8 & 0,22 \\
\hline 3 & 1697 & 1383 & 7,82 & 27,4 & 0,31 \\
\hline
\end{tabular}

ния отливки. Образцы для механических испытаний вырезались во всех отливках из аналогичных зон. Механические свойства образцов, полученных при различных скоростях охлаждения, определялись в отливках после термической обработки. Термическая обработка отливок производилось по режиму: $\mathrm{T}_{\text {закалки }}=1040{ }^{\circ} \mathrm{C}, \mathrm{T}_{\text {1-го отпуска }}=620^{\circ} \mathrm{C}, \mathrm{T}_{\text {2-го отпуска }}=550{ }^{\circ} \mathrm{C}$.

\section{Механические свойства отливок}

Механические свойства в отливках, полученных в кокиле с принудительным охлаждением донной части (№ 1), несколько выше, чем в отливках в условиях обычного охлаждения (№ 2) и в отливках с принудительным охлаждением дна без шлака между залитым металлом и кокилем (№ 3) (табл. 2). Наблюдается, что при малых скоростях охлаждения, за счет сформировавшейся укрупненной структуры происходит ухудшение механических свойств.

\section{Выводы}

1. Построенные модели распределения температурных полей в отливках, полученных ЭКЛ в различных условиях кристаллизации, позволяют спрогнозировать структурное состояние металла и морфологию распределения фаз.

2. При литье с отсечкой шлака и дополнительным управлением теплового поля можно получить высокие механические свойства, в отливках.

Статья подготовлена по материалам доклада, представленного на международном конгрессе «Цветные металль и минералы», ХХІІІ конференция "Алюминий Сибири», 2017 z.

\section{Список литературы}

[1] Медовар Б.И., Шевцов В.Л., Мартын В.М. и др.; Под ред. Патона Б.Е., Медовара Б.И. Электрошлаковая тигельная плавка и разливка металла. Киев.: Наук. думка, 1988. 214 с. [Medovar B.I., Shevtsov V.L., Martin V.M., etc Electroslag crucible melting and pouring Metal.; Under the editorship of Patton B.E., Medovara B.I. Kiyev, Sciences thought, 1988. 214 p. (in Russian)].

[2] Ларионова Н.В., Токмин А.М. Исследование влияния тепловых процессов при кристаллизации на структуру и свойства штамповой стали 4Х5МФС, Сборник докладов IX международного конгресса «Цветные металль и минералы», ХХІІІ конференция «Алюминий Сибири», 2017, 584-590. [Larionova N.V., Tokmin A.M. Research of influence of thermal processes at crystallization on structure and properties of shtampovy steel H11 the Collection of reports of the 
IX international congress "Non-ferrous Metals and Minerals", the XXIII conference "Aluminium of Siberia”, 2017, 584-590 (in Russian)].

[3] Ларионова Н.В., Токмин А.М., Свечникова Л.А., Синичкин А.М. Исследование тепловых процессов кристаллизации отливок электрошлакового кокильного литья. Литейное производство, 2016, 6, 22-25 [Larionova N.V., Tokmin A.M., Sinichkin A.M. The study of thermal processe of solidification of castings electroslag chill casting, Foundry production 2016, 6, 22-25 (in Russian)]. 